\title{
A NEW METHOD TO ASSESS PLATFORM CHANGES OVER SUCCESSIVE GENERATIONS OF PRODUCT VARIANTS FROM MULTIPLE DESIGN PERSPECTIVES
}

\author{
Wong, Foo Shing; Wynn, David C. \\ The University of Auckland
}

\begin{abstract}
This paper introduces a new method to help designers assess the impact of changes to a product platform when introducing a new variant. The method evaluates a platform design by investigating how changing some components will impact other platform design perspectives such as material, function, manufacturing processes and assembly time. To assess the usefulness of this method, it was applied to assess platform changes resulting from successive generations of scanner heads from two manufacturers. The method indicated that one manufacturer improved their scanner head design by improving the functionality of its components and assembly time. Whereas, the other manufacturer's new scanner head used more material and manufacturing processes without benefiting other design perspectives. Compared to existing product family evaluation methods which focus only on maximising commonality between product variants, the proposed method considers potential platform design improvements and assesses them from multiple design perspectives before deciding on reusing existing components or implementing the new design. The information from this method will also complement existing commonality indices.
\end{abstract}

Keywords: Platform strategies, Product families, Evaluation, Multiple design perspective, Generational design change

Contact:

Wong, Foo Shing

The University of Auckland

Mechanical Engineering

New Zealand

fwon360@aucklanduni.ac.nz

Cite this article: Wong, F.S., Wynn, D.C. (2019) 'A New Method to Assess Platform Changes Over Successive Generations of Product Variants from Multiple Design Perspectives', in Proceedings of the 22nd International Conference on Engineering Design (ICED19), Delft, The Netherlands, 5-8 August 2019. DOI:10.1017/dsi.2019.300 


\section{INTRODUCTION}

A common challenge in product development is to fulfil the different needs of each user with a limited amount of resources. To overcome this problem, multiple products may be designed with some resources shared between them. This design strategy is known as mass customisation (MC) (Miller and Elgard, 1998). These shared resources form a platform, which is the crux of a product family. Researchers often assess a platform design by assessing the number of resources shared across the product variants. Commonality indices are often used to measure the number of components shared between product variants. However, existing commonality indices assume a product family design process in which all variants are derived simultaneously from the same platform. As a result, they encourage standardising as much as possible. However, in practice, standardisation is not the only factor that benefits a platform design because platform design improvements are also beneficial. These design improvements usually occur between variants because they are often released sequentially due to limited time and resources to develop them simultaneously (Alizon et al., 2007). Therefore, in practice, each variant will embody a different generation of the evolving platform (Fujita et al., 2009). By considering these limitations of existing commonality indices, this paper aims to introduce a method to assess product platform component changes that are iteratively developed from multiple design perspectives.

\section{BACKGROUND}

\subsection{Product family design process}

Researchers typically assume that designers derive product family variants from the same platform simultaneously as shown on the right of Figure 1 (Gonzalez-Zugasti et al., 2001). However, in practice designers develop and deploy variants sequentially which causes variants to have different platforms as shown on the left of Figure 1 (Alizon et al., 2007). As a result, the commonality between variants is lower in practice than it is under the simultaneous development assumption. The next section will briefly summarise existing approaches for assessing product families in the research literature.

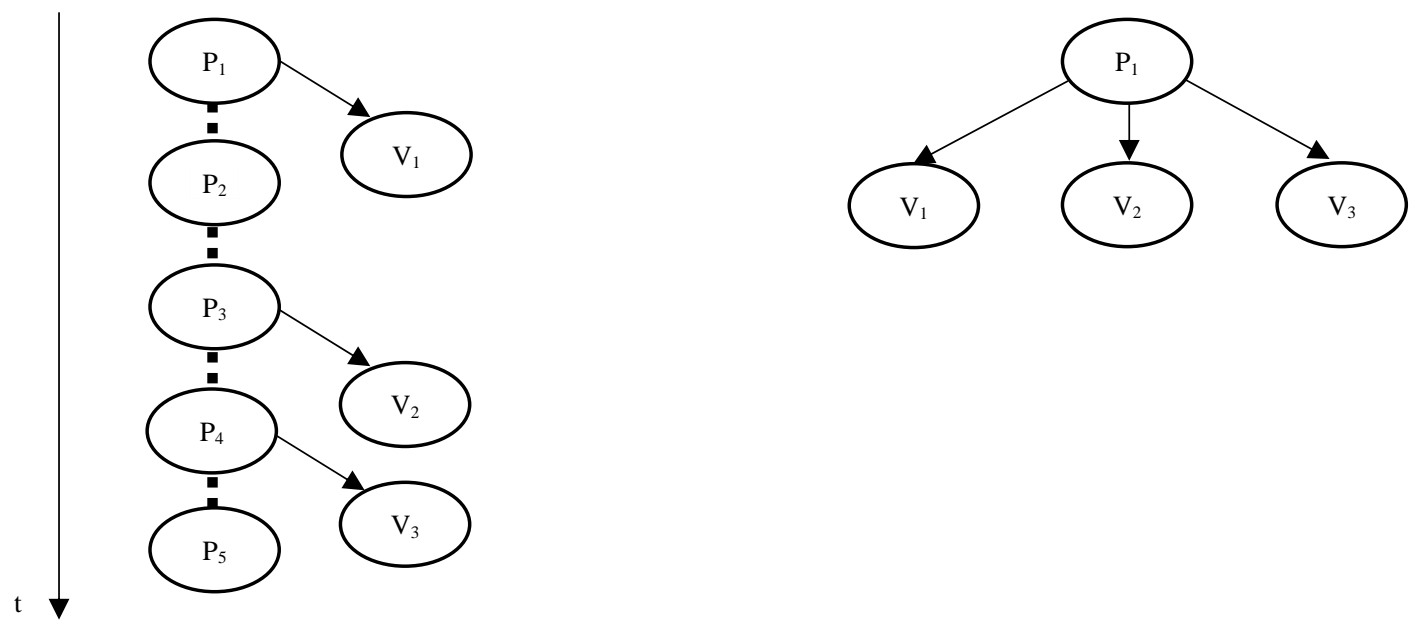

Figure 1. A comparison between practical and theoretical product family design process. $P x$ represents a platform while $V x$ represents a variant

\subsection{Measures of PPF production efficiency}

Researchers often use commonality indices (CIs) as a proxy to predict the amount of activity cost required to design, manufacture and assemble a new product variant (Martin and Ishii, 1996; Thevenot and Simpson, 2006). A high degree of commonality between variants indicates that a high proportion of components has been reused, implying that a firm can achieve greater economies of scale and scope (Tseng et al., 2017). However, complete commonality is impractical because of the need to differentiate the product variants to satisfy different customer needs. Table 1 summarises key commonality indices proposed in the research literature. The following sections will evaluate these existing measures of commonality and their limitations on assessing the production efficiency of platform derivatives. 
Table 1. Summary of commonality indices for assessing platform-based product families adopted from Thevenot and Simpson (2006) and Liu et al. (2013).

\begin{tabular}{|c|c|c|c|}
\hline Authors & Metric & Focus of analysis & Design perspective considered \\
\hline Colliers (1981) & DCI & $\begin{array}{l}\text { Common } \\
\text { components }\end{array}$ & $\begin{array}{l}\text { Number of common } \\
\text { components }\end{array}$ \\
\hline $\begin{array}{l}\text { Wacker and } \\
\text { Trelevan (1986) }\end{array}$ & TCCI & $\begin{array}{l}\text { Common } \\
\text { components }\end{array}$ & $\begin{array}{l}\text { Number of common } \\
\text { components }\end{array}$ \\
\hline $\begin{array}{l}\text { Martin and Ishii } \\
(1996,1997)\end{array}$ & CI & $\begin{array}{l}\text { Common } \\
\text { components }\end{array}$ & Number of unique components \\
\hline $\begin{array}{l}\text { Jiao and Tseng } \\
(2000)\end{array}$ & $\mathrm{CI}(\mathrm{c})$ & Cost & $\begin{array}{l}\text { Cost of component, production } \\
\text { volume, quantity of } \\
\text { components per operation }\end{array}$ \\
\hline $\begin{array}{l}\text { Siddique et al. } \\
\text { (1998) }\end{array}$ & $\% \mathrm{C}$ & Assembly & $\begin{array}{l}\text { Common components, } \\
\text { coupling, assembly workstation } \\
\text { and assembly sequences. }\end{array}$ \\
\hline Kota et al. (2000) & PCI & $\begin{array}{l}\text { Common non- } \\
\text { differentiating } \\
\text { components }\end{array}$ & $\begin{array}{l}\text { Size and shape of component, } \\
\text { materials and manufacturing } \\
\text { processes and assembly and } \\
\text { fastening scheme. }\end{array}$ \\
\hline $\begin{array}{l}\text { Thevenot and } \\
\text { Simpson (2006) }\end{array}$ & $\mathrm{CMC}$ & $\begin{array}{l}\text { Cost and Common } \\
\text { non-differentiating } \\
\text { components }\end{array}$ & $\begin{array}{l}\text { Size and shape of component, } \\
\text { materials and manufacturing } \\
\text { processes and assembly, } \\
\text { fastening scheme and cost of } \\
\text { component. }\end{array}$ \\
\hline $\begin{array}{l}\text { Alizon et al. } \\
\text { (2006) }\end{array}$ & CDI & $\begin{array}{l}\text { Common non- } \\
\text { differentiating } \\
\text { components }\end{array}$ & $\begin{array}{l}\text { Component/functional } \\
\text { commonality and variety }\end{array}$ \\
\hline
\end{tabular}

In Table 1, the Degree of Commonality Index (DCI), Total Constant Commonality Index (TCCI) and Commonality Index (CI) focus on the number of common components in a product family and they each output a single value to represent the overall commonality of the product family. Collier (1981) created the first CI called DCI which measures the average number of parent components reused from the total number of distinct components in a product family. However, DCI does not have a fixed range which made benchmarking between product families difficult for designers. Hence, Wacker and Trelevan (1986) and Martin and Ishii $(1996,1997)$ modified the DCI to create TCCI and CI, respectively. These two indices have a range between zero and one to enable benchmarking between product families. The difference between TCCI and CI is that TCCI is the ratio of the number of common components to the total number of components in a product family, whereas $\mathrm{CI}$ is the number of unique components to the total number of components in a product family. Component Part Commonality $(\mathrm{CI}(\mathrm{C}))$ is another commonality index derived from DCI. It additionally considers factors such as the price of components, the number of finished goods and the number of unique components when determining the degree of commonality. The index considered these factors because standardising costly components have a greater impact than standardising cheap components. Other than cost, Siddique et al. (1998) proposed an index called Percentage Commonality Index (\%C) which focused on the commonality of components, coupling, assembly workstation and assembly sequences.

More recently, some authors emphasised that variant and unique modules are essential elements of a product family which cannot be made common (Kota et al., 2000; Thevenot and Simpson (2006)). Therefore, these researchers created the Product Line Commonality Index (PCI) and Comprehensive Metric for Commonality (CMC) which only base commonality on the total number of nondifferentiating components. In other words, components and parameters that are supposed to be unique do not influence the degree of commonality in these metrics. Both PCI and CMC factor in the commonality in size, shape and material of the component, manufacturing processes and assembly and fastening schemes. The only difference between PCI and CMC is that CMC considers the cost of the components whereas PCI does not; CMC can be viewed as a combination of PCI and \%C (Thevenot and Simspon, 2007). From the perspective of this paper, although PCI and CMC account for spatial 
variety (unique and differentiating modules), they do not account for generational variety (design improvements). As a result, they penalise product variants with different platforms.

Unlike other CIs that only focus on measuring commonality, CDI measures the level of commonality and variety of components based on the whether the actual components of a product variant are classified in the same category (common, differentiated or unique) as the ideal components of an ideal variant (Alizon et al., 2006). Since this index can assess each component individually, it will be able to assess whether the degree of commonality and variety is appropriate for each product variant even if they each had different components as their platform. However, this index cannot assess whether a change in the commonality and variety of functions or components will improve production efficiency of the product family.

To summarise, all existing CIs suggest the same design perspective, which is to standardise as much non-value adding components as possible, based on the component's cost, material, size, shape, manufacturing and assembly processes. However, these indices do not assess whether the design changes required for generating platform derivatives might be beneficial for production before they recommend standardising a component of a platform. This paper contributes towards this gap.

\section{PRELIMINARY CASE STUDY EXAMPLE}

A case study was undertaken to investigate the ability of current metrics to capture production implications of progressively-developed product families and to investigate the needs for an improved approach.

Scanner heads in desktop printers were selected for the case study. Two printers, representing successive variants in competing product lines, from each of two manufacturers (HP and Canon), were selected for analysis. For this case study, only the printer scanner heads are used because (1) it is a module of a platform which exists across all variant of different generations and models which makes it possible to track the scanner head development process given that variants are developed sequentially, (2) a scanner head design does not impact on consumer satisfaction which makes it a non-differentiating component; this eliminates the consumer satisfaction factor which simplifies the analysis and (3) scanner heads can be found in other printer brands and they also meet the first two aforementioned conditions which make it possible to test the reliability of the proposed framework.

HP printers were selected as they are known for developing platform-based product families (Meyer and Lenherd, 1997). Canon printer scanner heads were used as the second sample.

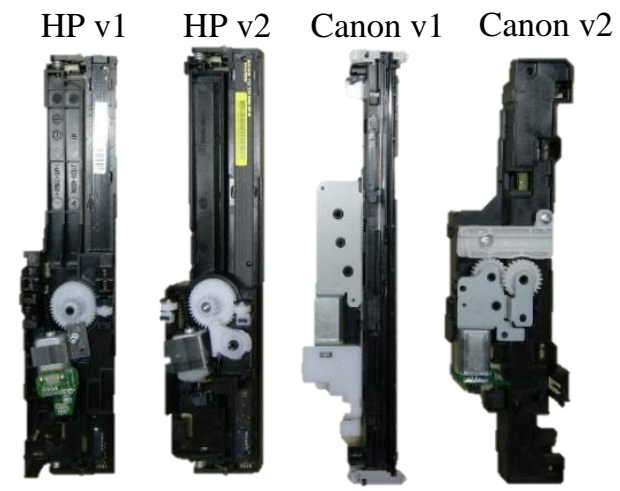

Figure 2. HP scanner heads (left) and Canon scanner heads (right)

The four scanner heads were disassembled to their constituent parts and compared to investigate commonality. In both printer companies, the two variants studied had a few different components even though they are non-value adding (in that the variants provide the same functionality) as shown in Figure 2. Initial observations indicated that both HP's and Canon's physical design changes from variant 1 to variant 2 reduced assembly time and material usage. The assembly time for each scanner head was estimated by the amount of time it took for the researcher to fully assembly the scanner head 
unit. The quantity of material used was measured by weighing the components or by measuring the geometry of the components.

After observing the scanner heads, a commonality analysis was carried out. This analysis not only accounts for the component's physical commonality but also considers other design perspectives of functionality, material, assembly time and manufacturing processes; similar to the latest commonality index, the CMC, as outlined in Table 1. The formula for assessing commonality for each design perspective was:

$$
\begin{aligned}
\text { Commonality Index }= & \frac{\text { number of identical } x}{\text { total number of unique } x} \\
& \text { Where } x=\text { the type of design perspective }
\end{aligned}
$$

The commonality analysis began by analysing the physical similarity between the components. Components that were physically identical were categorised as common components. Whereas, components that are physically different were categorised as different components. After categorising all the components of the two scanner heads in this way, the commonality index from a physical perspective was calculated using the commonality index formula above as shown in Table 2. This was done for both of the product families considered.

\begin{tabular}{|c|c|}
\hline \multicolumn{2}{|l|}{ Common components } \\
\hline \multicolumn{2}{|l|}{ LED Strip } \\
\hline \multicolumn{2}{|l|}{ Motor } \\
\hline \multicolumn{2}{|l|}{ Encoder } \\
\hline \multicolumn{2}{|l|}{ Springs x 2} \\
\hline \multicolumn{2}{|l|}{ Plastic wheels x 2} \\
\hline \multicolumn{2}{|c|}{ Total number of common components: 7} \\
\hline \multicolumn{2}{|c|}{ Different components } \\
\hline HP v1 & HP v2 \\
\hline Helical gear & Helical gear \\
\hline Metal bracket & Metal bracket \\
\hline Plastic pusher & Plastic pusher x 2 \\
\hline Plastic housing & Plastic housing \\
\hline Plastic wheel cover x 2 & Plastic wheel cover x 2 \\
\hline Spring & Spring \\
\hline \multicolumn{2}{|c|}{ Total number of different components: 15} \\
\hline \multicolumn{2}{|c|}{ Total number of unique components: 22} \\
\hline Commonality index (ph & ve) $=7 / 22 \times 100=31.8 \%$ \\
\hline
\end{tabular}

Table 2. Commonality index calculation for the commonality from a physical perspective

Table 3. Comparison of HP's and Canon's commonality indices from multiple design perspectives

\begin{tabular}{|l|l|l|l|l|l|}
\hline $\begin{array}{l}\text { Design } \\
\text { perspective }\end{array}$ & Parts & Material type & Function & $\begin{array}{l}\text { Assembly } \\
\text { method }\end{array}$ & $\begin{array}{l}\text { Manufacturing } \\
\text { method }\end{array}$ \\
\hline HP CI & $31.8 \%$ & $100 \%$ & $83.3 \%$ & $31.8 \%$ & $83.3 \%$ \\
\hline Canon CI & $22.7 \%$ & $88.9 \%$ & $100 \%$ & $90.0 \%$ & $88.9 \%$ \\
\hline
\end{tabular}

The commonality index for the material type, function, assembly method and manufacturing method were calculated similarly. The analysis treated the commonality of each perspective independently. For instance, the functional commonality analysis categorised two components as common if they perform the same function regardless of their physical differences. To measure the remaining perspectives of function, material, assembly and manufacturing the following units were used, respectively: number of functions per component, material type, assembly method and manufacturing method. For example, both of HP's scanner head motor had a common assembly method because both of them are slotted into the housing. Whereas, their scanner head gears had different types of assembly method because one requires a screw to hold it in place while the other is simply slotted onto the shaft. 
The manufacturing perspective required study of each equivalent component from the two variants to figure out whether more or fewer manufacturing processes were applied to make each one. For example, although each HP scanner head had differently shaped gears, they both share the same manufacturing process, namely injection moulding.

The same commonality index analysis was applied to the Canon scanner head. Table 3 summarises the commonality indices for each perspective for both manufacturers. Despite the changes between the two analysed variants having arguably resulted in a better scanner head design for both HP and Canon on some criteria, such as assembly time as assessed by the researcher, they both have a low commonality index especially from the component perspective and, for HP, the assembly perspective $(31.8 \%)$. Therefore, this case study confirms that existing commonality indices are not able to fully capture the beneficial effects of design changes that occur between successive product variants because they always imply such changes are undesirable.

\section{THE PROPOSED METHOD TO ASSESS PRODUCT PLATFORM COMPONENT CHANGES}

Unlike existing indices which encourage maximising the commonality between all platform components, the proposed method analyses the changes between each successive generation of a platform, considering several design perspectives. Figure 3 provides an outline of the proposed method.

The analysis begins by identifying components of a platform that are physically different between two generations of variants. These components are then listed in a table as the row headings. Platform components that are physically identical between the two variants are not listed in the table. The column headings contain the different design perspectives similar to the ones used in the preliminary case study: number of different types of material, material quantity, number of functions per component, assembly time and manufacturing processes. The table is completed by considering how the components in the newer generation of the platform have changed relative to the components in the earlier platform. The direction of change is specified for each design perspective using these values: $-1,0,+1$. For example, HP used less material to make their scanner head housing. Therefore, '-1' was used to describe the change in direction for material usage as shown in Table 4. Conversely, the value ' +1 ' was used to describe an increase in units for the particular perspective and ' 0 ' was used to describe no change in the units. The resulting table shows the impact of the changes in the physical components on the various design perspectives.

The second to last row of Table 4 and 5, called the overall design trends can be calculated by summing up the values in each column of the tables. The absolute value of each sum is then normalised to derive the percentages in the final row of Table 4 and 5. For example, in Table 4, the overall normalised design trend for assembly time is $33.3 \%$ because the value of ' -2 ' was firstly converted to an absolute value of ' 2 ' ' and then divided by the total number of components in the table which is six. Finally, words such as 'improved', 'worsen' and 'same' were used to describe the change in direction for each perspective. Arrows were also used to represent the direction of change. Continuing from the previous example, a green arrow pointing up is placed next to the value ' $33.3 \%$ Improved' to indicate that HP has improved its platform design from an assembly perspective.

To assess whether the proposed framework is capable of assessing platform design improvements and conclude whether a proposed platform design change is worth pursuing, the next section will apply the framework using the same set of HP and Canon printer scanner heads used in the case study example in Section 3. 


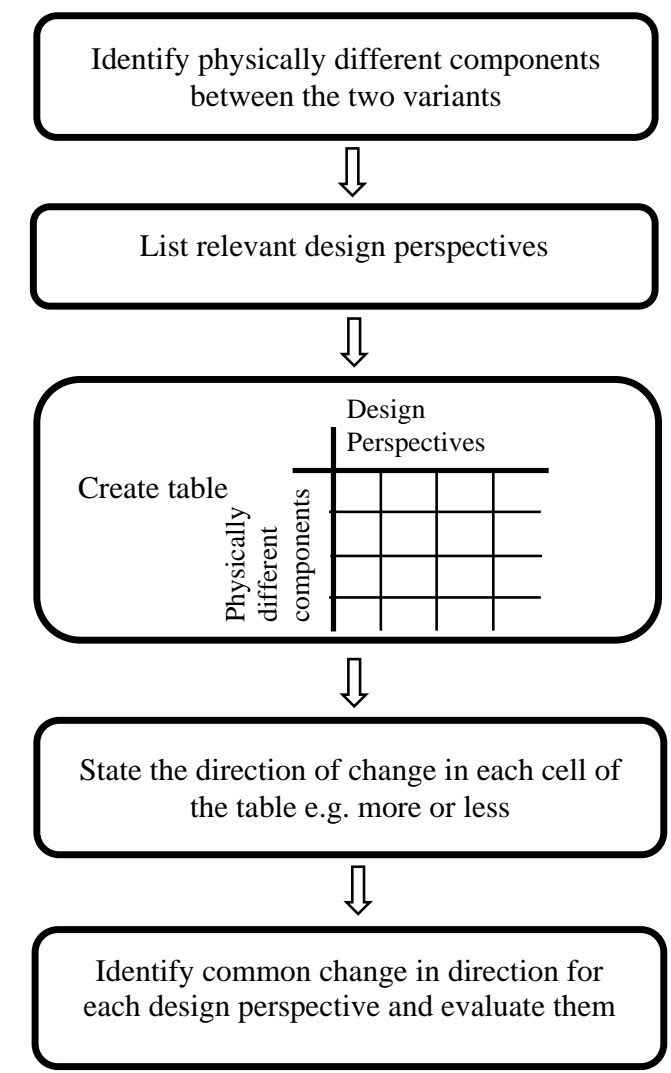

Figure 3. Steps for assessing product platform changes

\subsection{Case study: HP and Canon scanner head analysis}

This section applies the proposed framework to the two variants of the HP scanner head. The analysis begins by listing the parts that are different between the two scanner heads. The first column in Table 4 lists the parts that are different between the two versions of the HP scanner head. Next, the direction of change for each design perspective is stated qualitatively in the later columns of the table.

The assembly time for each scanner head was measured in seconds and compared against each other to see whether it improved or not. For instance, the assembly time for HP's gear increased because the new gear required a screw to hold it in place. Practitioner may use the Boothroyd and Dewhurst (2001) method to calculate the assembly time to obtain consistent data for each scanner head. For the manufacturing processes perspective, the direction of change requires the practitioner to observe each component to detect whether more or less manufacturing processes have been used to produce the component. HP's new metal bracket, for example, required fewer folding and stamping. Likewise, for the functional perspective, the practitioner will need to observe each component to determine whether physical changes have led the component to perform more or less function. A decrease in the number of functions for a component is more desirable for a platform because a more modular platform is more susceptible to future changes (Beek et al., 2010; Bonvoisin et al., 2016). In other words, a oneto-one relationship where one component performs one function is considered most preferable. For example, HP's old scanner head metal bracket held the motor and helical gear while their new version only holds the motor in place and does not make contact with the gear. Since the gear is now independent from the metal bracket, this arguably increases the likelihood that any future modifications might be possible without impacting its surrounding components. Lastly, from a material perspective, it is more preferable to have more components in a platform module to be made with the same type of material. For instance, the second version of the Canon scanner head is better than their first version, from a material perspective, because the newer scanner head housing was made entirely with plastic whereas the former was made with plastic and metal. 
After analysing the changes of components for each perspective, designers can sum up the values in each column, normalise them and add in arrows to show whether the perspective remains the same, is improved or worsens. The overall design trend row can also show the relationship between the design perspectives. As shown in Table 4, the arrows indicate that HP managed to increase modularity of their new scanner head architecture without increasing the assembly time and the number of manufacturing processes for most of their components. These design perspective relationships were not as obvious to identify if the analysis only relied on the initial observations outlined in Section 3.

The same analysis was carried out on Canon's scanner head. The results from Table 5 suggest that Canon also improved their scanner head as shown on the criteria in the table because they reduced material, assembly time and manufacturing processes. These results are based only on the design perspectives shown - in reality, there may have been additional issues and evaluation factors considered by the designers, that were not captured in this analysis.

Table 4. Table showing the impact of the physically different components on other design perspectives for the HP scanner head. Platform components that are identical between the scanner heads are not listed in the table

\begin{tabular}{|c|c|c|c|c|c|}
\hline & $\begin{array}{l}\text { Number of } \\
\text { different } \\
\text { types of } \\
\text { material }\end{array}$ & $\begin{array}{l}\text { Quantity of } \\
\text { material }\end{array}$ & $\begin{array}{l}\text { Number of } \\
\text { functions per } \\
\text { component } \\
\text { (modularity) }\end{array}$ & $\begin{array}{l}\text { Assembly } \\
\text { time }\end{array}$ & $\begin{array}{l}\text { Number of } \\
\text { manufacturing } \\
\text { processes }\end{array}$ \\
\hline Helical gear & 0 & +1 & 0 & +1 & -1 \\
\hline Metal bracket & 0 & +1 & -1 & 0 & -1 \\
\hline Plastic pusher & 0 & +1 & 0 & -1 & -1 \\
\hline $\begin{array}{l}\text { Plastic } \\
\text { Housing }\end{array}$ & 0 & -1 & 0 & 0 & -1 \\
\hline $\begin{array}{l}\text { Plastic wheel } \\
\text { cover }\end{array}$ & 0 & -1 & 0 & -1 & -1 \\
\hline Spring & 0 & -1 & 0 & -1 & 0 \\
\hline $\begin{array}{l}\text { Overall design } \\
\text { trend }\end{array}$ & 0 & 0 & -1 & -2 & -5 \\
\hline $\begin{array}{l}\text { Overall } \\
\text { normalised } \\
\text { design trend }\end{array}$ & $\begin{array}{c}0 \% \\
\text { Same }\end{array}$ & $\begin{array}{l}0 \% \\
\text { Same }\end{array}$ & $\begin{array}{c}16.7 \% \\
\text { Improved }\end{array}$ & $\begin{array}{l}33.3 \% \\
\text { Improved }\end{array}$ & $\begin{array}{l}83.3 \% \\
\text { Improved }\end{array}$ \\
\hline
\end{tabular}

Table 5. Table showing the impact of the physically different components on other design perspectives for the Canon scanner head. Platform components that are identical between the scanner heads are not listed in the table

\begin{tabular}{|l|c|c|c|c|c|}
\hline & $\begin{array}{l}\text { Number of } \\
\text { different } \\
\text { types of } \\
\text { material }\end{array}$ & $\begin{array}{l}\text { Quantity of } \\
\text { material }\end{array}$ & $\begin{array}{l}\text { Number of } \\
\text { functions per } \\
\text { component } \\
\text { (modularity) }\end{array}$ & $\begin{array}{l}\text { Assembly } \\
\text { time }\end{array}$ & $\begin{array}{l}\text { Number of } \\
\text { Manufacturing } \\
\text { processes }\end{array}$ \\
\hline Gears & 0 & -1 & 0 & 0 & 0 \\
\hline Metal bracket & 0 & -1 & 0 & 0 & +1 \\
\hline $\begin{array}{l}\text { Plastic rail } \\
\text { slider }\end{array}$ & 0 & -1 & 0 & 0 & -1 \\
\hline Housing & -1 & -1 & 0 & -1 & -1 \\
\hline $\begin{array}{l}\text { Overall design } \\
\text { trend }\end{array}$ & -1 & -4 & 0 & -1 & -1 \\
\hline $\begin{array}{l}\text { Overall } \\
\text { normalised } \\
\text { design trend } \\
\text { normalised }\end{array}$ & $\begin{array}{c}\text { Improved } \\
\text { 25\% }\end{array}$ & $\begin{array}{c}\text { Improved } \\
\text { Imprame }\end{array}$ \\
\hline
\end{tabular}




\section{DISCUSSION AND CONCLUSION}

Existing product family evaluation methods are based on the assumption that all variants are derived from the same platform simultaneously, which led to the idea of maximising commonality. In this case, the optimal platform design is one that is used across all variants. However, in practice, variants are often released sequentially, and designers will continuously improve their platform with each new variant. As a result, maximising commonality is not the only advantage because improving a platform design by introducing changes from one variant to the next also has potential benefits. Therefore, in this paper, a method is introduced to help assess whether it is more beneficial to reuse existing components or introduce newly-designed components. This is achieved by assessing a proposed platform design from different design perspectives and summarising the relationship between each design perspective.

The information from this method can also be used complementarily with existing commonality indices. For example, although Table 3 indicates that the HP scanner head had a low assembly commonality of $31.8 \%$, Table 4 justifies this by showing that the reduction in commonality was due to the component changes of the helical gear, plastic pusher and wheel cover which resulted in an improvement in assembly. Similarly, Table 5 explains Canon's low material commonality (88.9\%) in Table 3 by showing that Canon was able to make their new scanner head entirely from plastic instead of using a combination of metal and plastic which reduced material cost and consequently a reduction in the assembly time and the number of manufacturing processes.

\section{FUTURE WORK}

Although the results were promising, the new method needs to be applied to other product families for different types of products to investigate the breadth of applicability. Future work to improve the framework includes using an appropriate scale instead of words, e.g., a Likert 5- or 7-point scale, to describe the magnitude of the design change which will improve the accuracy of the tables. In addition, implementing a weighting function to the proposed method will enable designers to rank the importance of each design perspective. Additional future work includes considering change propagation of platform elements. This is because some components in a platform depend on one another which means the decision to reuse or redesign involves assessing multiple components instead of one. Another consideration would be to assess the trade-off between assembly time and manufacturing processes resulting from design changes by considering the company's cost structure.

\section{REFERENCES}

Alizon, F., Shooter, S. B. and Simpson, T. W. (2006), "Assessing and improving commonality and diversity within a product family", Paper presented at the ASME 2006 International Design Engineering Technical Conferences and Computers and Information in Engineering Conference. https://doi.org/10.1115/detc2006-99499

Alizon, F., Shooter, S. B. and Simpson, T. W. (2007), "Improving an existing product family based on commonality/diversity, modularity, and cost”, Design Studies, Vol. 28 No. 4, pp. 387-409. https://doi.org/10.1115/detc2006-99536

Bonvoisin, J., Halstenberg, F., Buchert, T. and Stark, R. (2016), “A systematic literature review on modular product design", Journal of Engineering Design, Vol. 27 No. 7, pp. 488-514. https://doi.org/10.1080/09544828.2016.1166482

Boothroyd, G., Dewhurst, P. and Knight, W. A. (2001), Product Design for Manufacture and Assembly, revised and expanded, CRC press. https://doi.org/10.1201/9780824741587

Collier, D. A. (1981), "The measurement and operating benefits of component part commonality", Decision Sciences, Vol. 12 No. 1, pp. 85-96. https://doi.org/10.1111/j.1540-5915.1981.tb00063.x

Fujita, K., Akai, R. and Amaya, H. (2009), "Product Family Deployment Strategies under Different Types of Product Variety Design Circumstances", Paper presented at the DS 58-4: Proceedings of ICED 09, the 17th International Conference on Engineering Design, Vol. 4, Product and Systems Design, Palo Alto, CA, USA, 24.-27.08. 2009.

Gonzalez-Zugasti, J. P., Otto, K. N. and Baker, J. D. (2000), "A method for architecting product platforms", Research in engineering design, Vol. 12 No. 2, pp. 61-72. https://doi.org/10.1007/s001630050024

Hölttä-Otto, K. and Otto, K. (2006), "Platform concept evaluation", In Product Platform and Product Family Design, pp. 49-72, Springer. https://doi.org/10.1007/0-387-29197-0_4 
Jiao, J. and Tseng, M. M. (2000), “Understanding product family for mass customization by developing commonality indices", Journal of Engineering Design, Vol. 11 No. 3, pp. 225-243. https://doi.org/10.1080/095448200750021003

Johnson, M. D. and Kirchain, R. (2010), "Developing and assessing commonality metrics for product families: A process-based cost-modeling approach", IEEE Transactions on Engineering Management, Vol. 57 No. 4, pp. 634-648. https://doi.org/10.1007/978-1-4614-7937-6_19

Kota, S., Sethuraman, K. and Miller, R. (2000), “A metric for evaluating design commonality in product families”, Journal of Mechanical Design, Vol. 122 No. 4, pp. 403-410. https://doi.org/10.1115/1.1320820

Liu, Y., Lim, S. C. J. and Lee, W. B. (2013), "Product family design through ontology-based faceted component analysis, selection, and optimization", Journal of Mechanical Design, Vol. 135 No. 8, p. 081007. https://doi.org/10.1115/1.4023632

Luo, X., Tang, J. and Kwong, C. (2014), “A QFD-Based Optimization Method for Scalable Product Platform”, In Advances in Product Family and Product Platform Design, pp. 343-365, Springer. https://doi.org/10.1007/978-1-4614-7937-6_14

Martin, M. V. and Ishii, K. (1996), "Design for variety: a methodology for understanding the costs of product proliferation", Paper presented at the Proceedings of The 1996 ASME Design Engineering Technical Conferences and Computers in Engineering Conference, California.

Meyer, M. H. and Lehnerd, A. P. (1997), The power of product platforms, Simon and Schuster.

Miller, T. D. and Elgard, P. (1998), "Defining modules, modularity and modularization", Paper presented at the Proceedings of the 13th IPS research seminar, Fuglsoe.

Siddique, Z., Rosen, D. W. and Wang, N. (1998), "On the applicability of product variety design concepts to automotive platform commonality”, Paper presented at the ASME Design Engineering Technical Conferences-Design Theory and Methodology.

Thevenot, H. J. and Simpson, T. W. (2006), "Commonality indices for product family design: a detailed comparison”, Journal of Engineering Design, Vol. 17 No. 2, pp. 99-119. https://doi.org/10.1080/09544820500275693

Thevenot, H. J. and Simpson, T. W. (2007), "A comprehensive metric for evaluating component commonality in a product family”, Journal of Engineering Design, Vol. 18 No. 6, pp. 577-598. https://doi.org/10.1115/detc2006-99268

Tseng, M. W., Yue and J Jiao, Roger. (2017), “Mass Customization”, https://doi.org/10.1007/978-3-642-359507_16701-3.

Van Beek, T. J., Erden, M. S. and Tomiyama, T. (2010), "Modular design of mechatronic systems with function modelling", Mechatronics, Vol. 20 No. 8, pp. 850-863. https://doi.org/10.1016/j.mechatronics.2010.02.002

Wacker, J. G. and Treleven, M. (1986), "Component part standardization: an analysis of commonality sources and indices”, Journal of Operations Management, Vol. 6 No. 2, pp. 219-244.

https://doi.org/10.1016/0272-6963(86)90026-4 